$\begin{array}{ll}\text { Abstracta Iranica } & \begin{array}{l}\text { Abstracta Iranica } \\ \text { Revue bibliographique pour le domaine irano-aryen }\end{array} \\ & \text { Volume } \mathbf{2 8} \mid \mathbf{2 0 0 7} \\ & \text { Comptes rendus des publications de } \mathbf{2 0 0 5}\end{array}$

\title{
Nation-Building Unraveled?: Aid, Peace and Justice in Afghanistan. Bloomfield, Kumarian Press, 2005, $256 \mathrm{p}$.
}

Anicée Van Engeland

\section{OpenEdition}

Journals

Édition électronique

URL : http://journals.openedition.org/abstractairanica/19751

DOI : 10.4000/abstractairanica. 19751

ISSN : 1961-960X

Éditeur :

CNRS (UMR 7528 Mondes iraniens et indiens), Éditions de l'IFRI

Édition imprimée

Date de publication : 15 mai 2007

ISSN : 0240-8910

Référence électronique

Anicée Van Engeland, « Nation-Building Unraveled?: Aid, Peace and Justice in Afghanistan. Bloomfield, Kumarian Press, 2005, 256 p. », Abstracta Iranica [En ligne], Volume 28 | 2007, document 460, mis en ligne le 18 septembre 2007, consulté le 25 septembre 2020. URL : http://journals.openedition.org/ abstractairanica/19751 ; DOI : https://doi.org/10.4000/abstractairanica.19751

Ce document a été généré automatiquement le 25 septembre 2020

Tous droits réservés 


\title{
Nation-Building Unraveled?: Aid, Peace and Justice in Afghanistan. Bloomfield, Kumarian Press, 2005, 256 p.
}

\author{
Anicée Van Engeland
}

1 Écrit par des acteurs humanitaires de terrain, ce livre décrit avec justesse les enjeux humains qui se jouent en Afghanistan depuis le début de la guerre. En effet, la guerre en Afghanistan a des conséquences importantes sur la notion d'intervention humanitaire, d'établissement d'un état de droit, de réforme d'un système juridique, de l'éducation aux droits de l'homme et de reconstruction. Sont aussi passés aux cribles le rôle des organisations internationales et le rôle des organisations locales et de la société civile.

2 Y sont analysés le rôle de l'aide internationale en Afghanistan, la transition du chaos vers la justice, la notion de «peacebuilding » et son développement depuis les accords de Bonn ; les AA. analysent aussi la marginalisation des droits de l'homme dans le pays ainsi que la lutte menée par les organisations internationales mais aussi les forces armées étrangères pour gagner la confiance des Afghans. La situation des femmes afghanes fait l'objet d'une étude spéciale dans l'ouvrage. Enfin, le cas humanitaire afghan permet de tirer des conclusions plus générales comme le rôle de l'humanitarisme dans le monde de l'après-11 septembre 2001, les dilemmes que posent l'assistance humanitaire comme la dépendance des populations et l'immixtion du politique dans l'humanitaire.

3 Cet ouvrage vise à contribuer au débat sur les conséquences juridiques de la guerre en Afghanistan et de la présence massive des humanitaires; il est utile tant aux experts qu'aux étudiants. 
INDEX

Thèmes : 13.2. Afghanistan

\section{AUTEURS}

ANICÉE VAN ENGELAND

Paris 